\title{
Poverty and Income Distribution \\ Data for measuring poverty and inequality changes \\ in the developing countries
}

\author{
Gary S. Fields \\ Cornell University
}

\begin{abstract}
How does income distribution change with economic growth? I distinguish between two aspects of income distribution poverty and inequality - and discuss how to measure each. I then review what data we would want and what data we have on changes in poverty and inequality in different countries. I conclude with suggestions on how to overcome some of the current data deficiencies.
\end{abstract}

Key words: Poverty; Inequality; Economic development

\section{Introduction}

A conference on the data base for development analysis gets to the very heart of what we mean by 'development'. The standard studies of countries' development performances and prospects typically go into great detail about various aspects of macroeconomic conditions (growth, investment, balance of payments, etc.); they give little or no attention to changes in income distribution. This omission is regrettable. To my mind, the most important data for assessing whether economic development is taking place is information on who has benefited how much from economic growth and, alas, who has been hurt how much by economic decline.

Income distribution data are put to a variety of uses including measuring income differences among various groups in the population, characterizing the poor, designing antipoverty efforts, and forecasting the potential for social strife. While all these are important, the most important use of distributional data, and the one on which this paper focuses, is the measurement of changes over time. Are people making material progress? Are there fewer poor and are those who remain in poverty getting less poor? How unequal are economic conditions and how is this changing over time?

The answers to these questions require data on changes in poverty and inequality, which are different aspects of the 'distribution of income'. 'Poverty' denotes the inability of an individual or a family to command sufficient resources to satisfy basic needs. The poverty line is a constant real amount below which persons are said to be poor; it is defined by the standards of a particular country at a particular stage of its economic development. Once it is determined who is poor and who not, the extent of poverty in a country may then be gauged by variables such as the number who are poor and the extent of their resource shortfall. 'Inequality', by its very nature, entails a comparison of economic positions. Relative income inequality measures such as the income shares of particular percentile groups, Gini coefficients, and Lorenz curves work with recipients' incomes as percentages of others' incomes or of the mean. Data on changes in poverty and inequality 
convey more direct information on changes in economic wellbeing than do data on the usual macroeconomic aggregates. ${ }^{1}$

Two issues must be faced by researchers interested in knowing how poverty and inequality have changed over time. The first is to decide what to try to measure; the second is to assemble the best available data on those measures. Unfortunately, the gap between what is desirable and what is available is enormous. Suggestions are offered on what can be done within a reasonable amount of time to improve the data base.

\section{Definition and measurement issues}

\subsection{The distribution of what?}

It is sometimes possible to decide what income distribution data to collect or, if different types of data have been collected, which ones to report and analyze. The most basic requirement for measuring changes in poverty and/ or inequality is data consistency, i.e., that the same thing be measured over time. In those cases in which comparable household surveys are conducted over time, decisions must be made about what to measure the distribution of. The following issues arise:

Income or consumption? Conceptually, consumption is a better basis for determining economic status than is income. This is because income may be temporarily high or low, and the spending unit may try to smooth its consumption across seasons or years by saving or dissaving as needed. However, we often have only income distributions and not consumption distributions, because only income questions are asked in many surveys. In such cases, it is better to use income information than nothing at all.

Imputations. In those countries in which the household surveys ask questions such as, "What was your income in pesos last week?' we have no choice but to use cash income as the basis for our poverty and inequality calculations. But when non-cash income information is available, it would be desirable to impute values for food and other goods produced and consumed at home, basic goods provided free or at subsidized rates by the government (e.g., free rations of the staple food), and goods or services provided by the employer (such as housing and meals).

Choice of recipient unit. Sometimes it is possible to choose whether to look at the individual, the family, or the household. ${ }^{2}$ In these cases, the use of larger units is better. When this is done, low-earning individuals are not classified as poor if they are members of high-earning families. This is appropriate to the extent that these individuals share in the family income, which is usually the case. However, this runs the risk of ignoring inequality within households. If the various members of a household consume different amounts of food, shelter, etc. in relation to needs, these differences are not picked up when the household is treated as the unit of observation. In order to be able to deal with these differences, we would need information on the specific consumption of specific items by each household member - information which is very

\footnotetext{
${ }^{1}$ Because poverty and inequality are different aspects of the distribution of income, phrases such as 'the income distribution worsened' are ambiguous. Is this supposed to mean that total national income fell? That everyone got poorer? That the fraction of people in poverty increased? That the distribution became more unequal? More precise terminology needs to be used.

2 The difference between 'family' and 'household' is that 'family' denotes a group of individuals related by blood or marriage whereas 'household' includes not only nuclear families but also groups of families or unrelated individuals living together and pooling their resources for purposes of meals and lodging (e.g., extended families).
} 
rarely available. For more on intrahousehold inequality, see Sen (1984) and Haddad and Kanbur (1990).

Adjustment for family size. Large families have greater needs than small families do. Therefore, an adjustment needs to be made for family size. Although different poverty lines might be defined for different family sizes (as in the United States), I know of no developing country that does this. What they all do is to adjust family size so that a single poverty line can be applied. The simplest and most straightforward way of making this adjustment is to express the poverty line on a per-capita basis and to compare a given household's per capita income or consumption with that amount. Differences in needs might also be allowed for by making the family adjustment on an adult-equivalent basis, though this has often proved to be problematical. For a thorough discussion of these issues, see Atkinson and Bourguignon (1987).

Time period covered. While a long reference period is more apt to capture permanent rather than transitory living standards, a short reference period minimizes recall and reporting error. A year is probably too long a reference period (unless reported annual amounts can be verified by payroll information or expense diaries) and a day too short. A week or a month would be better.

Regional differentiation. It is often the case in developing countries that the cost of living varies widely from one part of the country to another and particularly between urban and rural areas. Accordingly, countries such as India and Costa Rica have set separate rural and urban poverty lines, which is desirable to do when spatial cost of living differences are large. But along with regionally-distinct poverty lines comes the need for regionally-distinct inflation adjustments and regionallydistinct imputations for home-produced or employer-provided goods and services. The gains may not be worth the costs.

\subsection{Setting a poverty line}

The poverty line is meant to be a constant real amount below which an individual or family is said to be poor. Care must be taken to assure that the line used is in fact constant in real terms.

Figures on income or consumption need to be adjusted to reflect inflation. In some countries, an annual inflation adjustment is sufficient. However, in those with triple-digit inflation or high double-digit inflation, adjustments must be made more frequently, perhaps monthly or even weekly. Poverty lines must be inflation-adjusted too. In those countries where separate cost- of-living indicators are available for high-income, middle-income, and low-income households, it is evident that the low-income cost-of-living factor should be used to adjust the poverty line over time. Otherwise, the options are to use a national inflation rate or to use one or more components of that rate, for instance, the increase in the food-price index. Which to use depends upon the composition of the market-basket used to construct the national consumer price index and the share of the poor's consumption devoted to food or other specific items.

Absolute poverty measures take the poverty line to be constant in terms of real purchasing power. Such a conception implies that the only adjustment to be made to the poverty line over time is an adjustment for inflation. In particular, we should not do as some suggest and increase the poverty line by the rate of economic growth; to do this would cause us to lose the notion of poverty as a state of absolute economic deprivation.

Here are some illustrations of the kinds of poverty lines that have been used in developing countries, (i) The Economic 
Commission for Latin America and the Caribbean (CEPAL) considers two factors when determining the poverty line for Latin American countries: the cost of the basic food basket and the cost of non-food necessities. The basic food basket is determined by nutritional necessities, mainly the caloric value and protein content of food as well as current dietary habits. The cost of non-food necessities is estimated to be equal to the cost of the basic food basket in each country, so that the poverty line is double the basic food budget. CEPAL's 'poverty line' is the figure just described, while the 'indigency line' is the amount needed just for food but not for other items; see CEPAL (1990) for further details, (ii) The Indian Poverty Line has long been defined as the amount of income needed to purchase a minimally adequate diet. The family income required to achieve this diet is figured by estimating the cost of this diet per adult, adjusting for family makeup, expanding to a requisite family income figure using the ratio of food to nonfood expenditures, and dividing by family size to obtain a per capita amount. The urban poverty line is about $20 \%$ higher than the rural poverty line, reflecting the higher cost-ofliving in urban areas. For details, see Bardhan (1974).

These approaches exemplify how international agencies and individual countries have endeavored to set the poverty line in terms of the resources needed to purchase the necessities of life. Although there are difficult issues in determining scientifically what exactly are the necessities of life, poverty lines determined in this way are nonetheless better than the arbitrary reference lines used elsewhere. In Brazil, for instance, income distributions are regularly reported as multiples of the minimum wage. ${ }^{3}$ This poses two problems. One is that the Brazilian minimum wage, like other countries', is determined politically rather than by reference to basic human needs. The other is that the real minimum wage changes over time in Brazil (as elsewhere), and therefore the fraction of income recipients earning less than the current minimum can vary over time simply because the real minimum itself varies over time. Some researchers on Brazil have calculated poverty with just such a changing standard; others, however, have overcome this difficulty by taking as their standard the minimum wage of $19 x x$, adjusted for inflation.

A contentious issue is whether there should be a single poverty line for all of the developing countries or whether each country should use its own specific line. Internationally comparable poverty lines have been proposed by the World Bank in the 1990 WDR. The lower figure (U.S. \$275 per capita per year, termed 'extreme poverty') corresponds to a poverty line for India (converting local currencies to dollars using 1985 Purchasing Power Parity rates), while the higher figure (U.S. $\$ 350$ per year, termed 'poverty') falls in the middle of a range of countries including Bangladesh, Egypt, India, Indonesia, Kenya, Morocco, and Tanzania. While there are obvious advantages in using an internationally comparable standard, there is also a strong practical objection: some countries have their own well-established poverty lines and do not take kindly to the World Bank telling them that they have more poverty than they themselves say they have (unless, of course, the World Bank backs such statements with more development assistance). Furthermore, individual country poverty lines are well-established in the national political dialogue in places such as India and Malaysia and it is confusing to discuss poverty with the poverty line set elsewhere. ${ }^{4}$ As a practical matter in such cases, the national poverty lines have to be respected.

\footnotetext{
${ }^{3}$ Alas, the category with the highest frequency is 'less than one minimum wage'.

${ }^{1}$ Readers in the United States might similarly ask themselves how receptive they might be to using a poverty line other than the familiar Bureau of the Census one.
} 
Once a poverty line has been defined, the next step in measuring poverty is to determine how much poverty there is given that poverty line. This is the subject of Section 2.3.

\subsection{Measuring poverty ${ }^{5}$}

The simplest poverty measure is the poverty headcount, which tells how many people are poor. For instance, using the internationally-comparable poverty lines described above, the World Bank estimates that more than 1,100 million of the world's people are poor and more than 600 million extremely poor. The United Nations reports similar figures for the number who are absolutely poor in the world (Human Development Report 1990).

Almost as simple a measure is the fraction of households in poverty. This, the poverty headcount ratio, is typically the sole index of poverty calculated for a country, so researchers must make do with data on this one aspect of poverty change.

The poverty headcount and the poverty headcount ratio only tell how many individuals or families are poor, but not how severe is their poverty. For this reason, poverty researchers have long been interested in two other measures: the average income shortfall of the poor and the extent of income inequality among the poor. The higher is the average income shortfall of the poor, the more poverty there is said to be. As for the extent of income inequality among the poor, it might reasonably be said that poverty is increased by a disequalizing transfer among the poor, i.e., from a very poor person to a less poor person.

When the poverty headcount ratio and the average income shortfall are calculated, these two aspects of a country's poverty are usually presented separately. The degree of income inequality among the poor is hard to estimate from published tabulations, because the published tabulations typically do not include enough income categories among the poor.

These separate aspects of poverty - the headcount ratio, the average income shortfall, and the inequality among the poor - might be labeled as non-comprehensive poverty measures, since they tell us about different aspects of a country's poverty, though not all at once. The alternative is to calculate comprehensive poverty measures which take account of all three of these components simultaneously. This can be done when the original income distribution data are available in computerized form or published in a sufficiently large number of categories such as percentiles.

One good comprehensive measure is the Sen Poverty Index:

$$
S=H\left[I+(1-I) G_{p}\right.
$$

where $H$ is the poverty headcount ratio, $l$ is the average income shortfall of the poor in percentage terms, and $G_{p}$ is the Gini coefficient of income inequality among the poor (Sen, 1976). The Sen index is larger, (a) the higher is the headcount ratio, for any given average income shortfall and Gini coefficient among the poor; (b) the higher is the average income shortfall among the poor, for any given headcount ratio and Gini coefficient among the poor; and (c) the higher is the Gini

\footnotetext{
${ }^{5}$ For terminological convenience, I shall suppose in this section that poverty and inequality are defined and measured on the basis of household income per capita, and shall refer for shorthand to 'households' and to 'incomes' in what follows.
} 
coefficient among the poor, for any given headcount ratio and average income shortfall.

Another good comprehensive measure is the P-Alpha Poverty Index suggested by Foster et al. (1984). It is defined as:

$$
P_{\alpha}=\left(\frac{1}{n}\right) \sum_{i}\left[\frac{z-y_{i}}{z}\right]^{\alpha} \text { for all } y_{i}<z
$$

The term in brackets $\left[\frac{z-y_{i}}{z}\right]$ is the difference between the poverty line $(z)$ and the income of the ith poor household $\left(y_{i}\right)$, expressed as a percentage of the poverty line. The expression $\left[\frac{z-y_{i}}{z}\right]^{\alpha}$ is then the exponentiated income shortfall of the $i$ th household. These are then summed over all poor households and divided by the total population ( $n$ ) to yield the index $P_{\alpha}$.

The values of $\alpha$ of particular interest are $\alpha=0,1$, and 2 . Any value of a greater than one gives greater weight to a poorer person's poverty than to a less-poor person's poverty. One such weighting scheme would be to say that a household $60 \%$ below the poverty line receives a weight of $60 \%$, one $20 \%$ below the poverty line receives a weight of $20 \%$, and so on. These weights correspond to the $P_{\alpha}$ index with $\alpha$ equal to two. When $\alpha$ equals one, we no longer give a larger weight to larger poverty gaps; each income shortfall is weighted the same. The formula for $P_{\alpha}$ when $\alpha$ equals one simplifies to

$$
P_{1}=H I \text {. }
$$

With the $P_{1}$ measure, income inequality among the poor is deemed irrelevant. Finally, when $\alpha$ equals zero, each term in the summation is equal to one, and the poverty index is then the ratio of the number poor $(q)$ to the total population ( $n$ )

$$
P_{0}=q / n=H
$$

i.e., the headcount ratio. We see, therefore, that the $P_{\alpha}$ class can allow for larger poverty gaps to be given greater weight while at the same time nesting $H I$ and $H$ as special cases.

Many countries conduct repeated household surveys, either under the auspices of their national statistical offices or of the World Bank's LSMS and SDA units. For these countries, it would be a simple matter for the national statistical office or the international agency in charge to publish time series on the components of poverty $\left(H, l\right.$, and $\left.G_{p}\right)$ and the comprehensive measures of poverty $\left(S\right.$ and $\left.P_{2}\right)$. In the meantime, the research community must make do with what we have - most often, the headcount ratio and nothing more.

\subsection{Measuring inequality}

Inequality may be conceptualized in relative terms, absolute terms, or a mixed approach. By far the most common approach is the relative inequality approach, and that is the one followed here.

Relative inequality deals with comparisons of shares of income rather than dollar differences. The most comprehensive way of dealing with everyone's share is to compare Lorenz curves and to rank inequalities as the Lorenz criterion does 
when a Lorenz ranking is possible. ${ }^{6}$ When a Lorenz ranking is not possible, we have two options. One is to accept the incompleteness of the Lorenz ordering and say that we have nothing to say about whether inequality has gone up or down. This is not a popular position - most analysts want to say something even when Lorenz curves cross. In such a case, we should use an inequality measure which is Lorenz-consistent, i.e., one that ranks inequalities as Lorenz comparisons do whenever one distribution Lorenz-dominates another. Many commonly-used measures of inequality are Lorenzconsistent (the Gini coefficient, Theil's two measures, the Atkinson index, and the coefficient of variation) but not all are; those that are not include some which are only weakly Lorenz-consistent (including the income share of the richest $x \%$ or the poorest $y \%$ ) and others which are Lorenz-inconsistent (including the mean absolute deviation and the logarithm of the variance of incomes). The most commonly-used Lorenz- consistent inequality measure is the Gini coefficient, viz., the area between the Lorenz curve and the 45 degree line expressed as a fraction of the area between the 45 degree line and the axes.

Notwithstanding the extensive academic literature establishing the properties of the various inequality indices and discussing the merits of one Lorenz- consistent measure versus another, empirical researchers face a very limited data base. Lorenz curves are rarely presented, and often the information needed to compare Lorenz curves over time is not presented. As for the Lorenz-based inequality indices, if we are lucky, we have Gini coefficients calculated for us. If we are less lucky, we have the information from which we can calculate our own Gini coefficients. If we are less lucky yet, we cannot even do that. So although we might want to base our analyses of changing inequality on Lorenz comparisons or on inequality indices other than the Gini coefficient, the underlying data base does not now permit such comparisons to be made in more than a handful of developing countries.

\section{The state of data on poverty and inequality}

\subsection{What we want}

As described in Section 2, in order to be able to measure changing income distribution in the course of economic development, what we would want are measures of poverty and of inequality for two or more points in time. Such measures might include:

- Quantitative measures of poverty such as the headcount ratio, the Sen index, or the P-alpha index

- Quantitative measures of inequality such as the Gini coefficient or the income shares of particular percentile groups

- Ordinal inequality comparisons determining whether one income distribution Lorenz-dominates another

This is what we want. Leaving aside for the moment any discussion of data quality, what can we get?

\footnotetext{
${ }^{6}$ The Lorenz curve is a graphical depiction of the cumulative share of income received by each cumulative share of population (ordered from lowest income to highest). If the Lorenz curve for one distribution $A$ lies somewhere above and nowhere below the Lorenz curve for another distribution $B$, distribution $A$ is said to 'Lorenz-dominate' distribution $B$. If $A$ and $B$ represent a given country's income distribution at two different points in time, a 'Lorenz-improvement' is said to have taken place; inequality has fallen. Similarly, one distribution may be 'Lorenzinferior' to another; over time, this is a 'Lorenz-worsening', and inequality has risen. A third possibility, apart from Lorenz-improvements and Lorenz-worsenings, is that two Lorenz curves cross. In this case, the Lorenz criterion has nothing to say about inequality comparisons.
} 
One of the most accessible data sources is the table on income distribution published each year by the World Bank in its World Development Report. Several inadequacies arise:

- For most of the low-income and middle-income countries, no income distribution information at all is available.

- No information is presented on poverty.

- No summary measures of inequality, such as the Gini coefficient, are calculated.

- Changes over time are not presented.

Nor is the desired information is to be found in the World Bank's Social Indicators of Development, the United Nations' Human Development Report, UNICEF's The State of the World's Children, or the ILO's Yearbook of Labor Statistics. ${ }^{7}$ This is not to say that data on changes in poverty and inequality cannot be gotten, but rather that they have not been. The rest of this section talks about what to include and how.

\subsection{Criteria for data inclusion}

Various compilations of income distribution data have appeared over the years. These include Adelman and Morris (1973), Paukert (1973), Jain (1975), Ahluwalia et al. (1979), Fields (1980), United Nations (1981, 1985), ILO (1984), and Fields (1989). In addition, more information is scattered in country-specific sources such as national statistical yearbooks, reports on censuses and household surveys, country reports by national and international development agencies, and research studies.

In these sources, data have been found for 70 developing economies (not all of which are countries). These are: Argentina, Bahamas, Bangladesh, Barbados, Bermuda, Bolivia, Botswana, Brazil, Burma, Chad, Chile, China, Colombia, Costa Rica, Cote d'Ivoire (Ivory Coast), Dahomey, Dominican Republic, Ecuador, Egypt, El Salvador, Fiji, Gabon, Guatemala, Honduras, Hong Kong, India, Indonesia, Iran, Iraq, Jamaica, Kenya, Korea (Republic of), Lebanon, Libya, Madagascar (formerly Malagasy Republic), Malawi, Malaysia, Mauritius, Mexico, Morocco, Nepal, Niger, Nigeria, Pakistan, Panama, Papua New Guinea, Peru, Philippines, Puerto Rico, Reunion, Rwanda, Senegal, Seychelles, Sierra Leone, Singapore, Sri Lanka, Sudan, Surinam, Taiwan, Tanzania, Thailand, Trinidad and Tobago, Tunisia, Turkey, Uganda, Uruguay, Venezuela, Zambia, and Zimbabwe (formerly Rhodesia).

Before using the published income distribution estimates, it behooves the analyst to specify minimal standards for data admissibility. The following are the ones that I use:

i. The data base must be an actual household survey or census.

ii. The data must be national in coverage.

iii. For comparisons across time, the income concept (whether income or expenditure) and recipient unit (whether

\footnotetext{
7 The Social Indicators of Development 1991/92 contains data on changing poverty rates over time for precisely two countries in the world (Morocco and Pakistan) and no data on changes in inequality. The Human Development Report 1992 contains poverty headcount ratios and Gini coefficients for a large number of countries but no intertemporal data.
} 
household, individual, or per capita) must be constant.

These criteria are not stringent ones, and other desiderata might be added. What is lamentable is that even these three are often not fulfilled. It is instructive to consider how:

- Many countries' income distribution estimates are synthesized from a variety of sources. For example, several researchers have used income distribution estimates from Colombia for 1964 . These data come from a study by a leading Colombian economist, Miguel Urrutia, who has termed the 1964 data 'the earliest reliable income distribution' (Urrutia, 1985, p. 74). In actuality, there was no income distribution survey with national coverage in that year:

'Because rural household surveys were unavailable in the 1960s, the rural income distribution was calculated from four sources: the population census, data on value- added for farms of different sizes based on an agricultural production survey, information on wages of agricultural laborers, and data on the distribution of farms by size based on the 1960 census of agricultural production units'. (Urrutia, 1985, p. 76.)

Blending these various ingredients into an estimated rural income distribution necessarily entails strong assumptions about how to assign farm incomes to different households, how to allow for variability in wages paid to agricultural laborers, etc. This is the kind of synthetic estimate which is not based on an actual household survey. Because this fails the first criterion for data acceptability, I have not in my own work used any estimates for Colombia from the 1960s and before. ${ }^{8}$ For the same reason, I also recommend that the estimates which have been published for Argentina, Madagascar, and Malawi, among others, not be used.

Another way in which an income distribution might be created synthetically is to impose a particular functional form on the data. For example, the first published estimate of income distribution for Bolivia, by Adelman and Morris (1973), allocated incomes to the poorest $40 \%$ and the next $20 \%$ on the basis of the distributions in similar Latin American countries. In my view, the resultant estimates ought not to be used either. Likewise, many authors have estimated the income shares of particular percentile groups by assuming that the income distribution is, say, lognormal. This becomes problematical when the fitted distribution is used in place of the actual one.

- Many countries' data are not national in coverage. Often, the geographical coverage is urban areas only. ${ }^{9}$ The reason that this is a problem is that one way for the poor to overcome limited economic opportunities in one part of a country is to move to another part of the country. To find, for instance, that a higher percentage of the people of Gran Buenos Aires are poor does not necessarily imply that a higher fraction of all Argentinians are poor.

A generic problem arises also. Many income distribution estimates are based on data from establishment surveys, such as manufacturing firms employing at least ten workers. Such firms belong to the formal sector and are disproportionately urban. Consequently, the workers in those firms cannot be said to be representative of workers in the nation. Income distributions estimated from the workers in such firms give a distorted picture of the income distribution in the economy

\footnotetext{
${ }^{8}$ Since the early 1970s, Colombia has had a program of household surveys. Although most of these are limited to urban areas, a few were national in coverage. The national surveys for 1971, 1978, and 1988 have been used by Londono (1989) to provide income distribution data, from which inequality and poverty have been calculated.

${ }^{9}$ This is true of most of the data commonly presented for Argentina, Burma, Chile, Colombia, Libya, Papua New Guinea, Peru, Uruguay, and Venezuela, among others.
} 
as a whole.

One other use of sub-national data bears mention. Some researchers present information on changes in poverty for selected regions, occupations, or ethnic groups and often use such data to show that poverty has increased for members of these groups. Data based on such particularly-selected groups asks one question - are there groups that have become poorer? - whereas the more appropriate question is whether for all groups taken together the extent of poverty in a given country has increased or decreased over time.

- Finally, even when the income distribution figures are based on actual surveys with national coverage, some countries' estimates have not dealt with standardized concepts. In a study of Peru, Webb (1988) estimated changes in poverty and inequality from 1971/72 to 1985/86. The 1971/72 data come from a National Survey of Food Consumption, while the 1985/86 data come from a Living Standards Measurement Study. Two problems arise in comparing these two surveys. First, although both surveys were national in coverage, consumption evidently was counted differently in the two of them the LSMS appears to adopt a broader conception of consumption than did the NSFC. Second, the two surveys had different demographic units - the income distribution in one survey was based on tabulations of per capita consumption and in the other on family consumption unadjusted for family size. The inequality and poverty measures calculated from these very different data bases should not be compared with one another.

These three problems just mentioned - use of synthetic data or assumed functional forms, subnational coverage, and nonstandard concepts - are not just occasional occurrences. Of the seventy countries listed above, exactly half of the income distribution estimates failed to fulfill these three minimal criteria (Fields, 1989). In my view, these estimates are best set aside.

\subsection{How we can do better}

The problems mentioned in Section 3.2, although serious, are in the process of being overcome. Here are some of the improvements now in the works:

- I myself have brought out a more recent and comprehensive compilation of data in which the three preceding criteria for minimal acceptability appear to be satisfied (Fields, 1989). In that compilation, along with subsequent work for Latin America (Fields, 1992), changes in poverty and/or inequality are documented for the Bahamas, Bangladesh, Brazil, Chile, Colombia, Costa Rica, Egypt, Guatemala, Hong Kong, India, Indonesia, Jamaica, Korea, Malaysia, Mexico, Morocco, Pakistan, Panama, the Philippines, Puerto Rico, Singapore, Sri Lanka, Taiwan, Thailand, Trinidad and Tobago, Turkey, and Venezuela. I was also able to include data for a single year for a number of other countries: Colombia, Cote d'Ivoire, El Salvador, Fiji, Honduras, Iran, Nepal, Panama, Peru, Reunion, Seychelles, Sierra Leone, and Tunisia. For many of these countries, new surveys are now being administered, so that changes over time will be available in the coming years even though they are not now.

- The World Bank's 1990 WDR documented and analyzed changes in poverty that have taken place in Brazil, China, Colombia, Costa Rica, India, Indonesia, Malaysia, Morocco, Pakistan, Poland, Singapore, Sri Lanka, Thailand, Venezuela, 
and Yugoslavia. Information for these and other countries is continually being compiled by Martin Ravallion and collaborators and issued in working papers which are as-yet unpublished (Chen et al., 1993; Ravallion, 1993).

- The Economic Commission for Latin America and the Caribbean (known by its Spanish acronym, CEPAL) and the Interamerican Development Bank have estimated changes in poverty for ten Latin American countries. The results have appeared in various CEPAL publications (e.g., CEPAL, 1990; Altimir, 1993) and in an unpublished IDB working paper (Morley, 1992).

- The ILO has just issued a major new data source on income distribution in some sixty developed and developing countries (Tabatabai, 1993). This work is continually being updated to include the findings of poverty assessments done at the World Bank and elsewhere. Because this compendium is so new, the information in it is only now being analyzed. This promises to be a major data base from which changes in poverty rates can be gauged.

Despite the progress that has been made, the data on poverty and inequality in the developing countries remain hard to find. One of the international agencies with abundant resources should go through the underlying data country by country, apply appropriate selection criteria, and compile a reliable data base. One natural would be the World Bank. Development analysts now turn routinely to the World Development Report for information on growth of GNP and its components, trade, balance of payments, savings, and investment. Why not also a table on poverty and another on inequality for each country for each of a number of years? Another would be the ILO, whose Yearbook of Labor Statistics is regularly consulted by labor market analysts. It is absurd that such information would not be readily available.

If such information is presented, it might take the form shown in Table 1 for one developing country, Malaysia, which typifies the type of data that can now be gotten. The data are based on comparable censuses and surveys. The basis for the income distribution is household income, although not on a per capita basis. Inequality is measured by the Gini coefficient. The underlying data are presented in sufficiently rich detail so that Lorenz curves can be compared. Poverty is measured in reference to a nationally- determined constant real dollar amount. Changes over time in poverty are measured by the poverty headcount ratio.

Substantively, these data show that inequality in Malaysia wavered around moderate levels ${ }^{10}$ while poverty fell steadily. These were years of rapid economic growth in Malaysia. Thus, Malaysia is a country in which economic growth brought a pronounced reduction in poverty and no important change in inequality.

How general are these conclusions? In most other developing countries, we also lack comprehensive measures of poverty which are sensitive to the distribution of income among the poor as well as the number poor and we also lack data on Lorenz-comparisons and on several Lorenz-consistent inequality measures. Analysts of income distribution in these countries are perforce limited to comparisons of headcount ratios to measure poverty and Gini coefficients to measure inequality. Using these measures, Fields (1991) showed that economic growth nearly always reduces poverty; when poverty did not fall, it is usually because growth did not take place. As for inequality, there is no relationship between

\footnotetext{
${ }^{10} \mathrm{Gini}$ coefficients in the world range from just below 0.3 to just above 0.6 .
} 
growth and inequality: inequality increased as often as it decreased, and the direction of change is not related either to the level of national income or to its rate of growth.

But now, I am going beyond data for development analysis and getting into what the data show - a topic for another conference, not this one. 
Table 1

Malaysia

Data used

1970 Post-Enumeration Survey; 1977 Agricultural Census;

1980 Household Income Survey; 1984 Household Income Survey

Inequality

Gini coefficient of income among households

$\begin{array}{ll}1957 / 58 & 0.42 \\ 1970 & 0.50 \\ 1976 & 0.53 \\ 1979 & 0.51 \\ 1984 & 0.48\end{array}$

Lorenz changes between successive surveys

1957/58-1970 Lorenz-worsening

1970-1976 Lorenz-worsening

1976-1979 Lorenz-improvement

1979-1984 I orenz-improvement

Lorenz changes between the first available survey and the last 1957/58-1984 Lorenz-worsening

Poverty

Proportion of households with incomes below \$M 33 per capita, in 1970 prices

$\begin{array}{ll}1970 & 49.3 \% \\ 1976 & 39.6 \\ 1979 & 29.0 \\ 1984 & 18.4\end{array}$

Poverty changes between successive surveys

$\begin{array}{ll}1970-1976 & \text { Poverty fell } \\ 1976-1979 & \text { Poverty fell } \\ 1979-1984 & \text { Poverty fell }\end{array}$

Poverty change between the first available survey and the last 1970-1984 Poverty fell

Sources

For Gini coefficients: Henry Bruton, The political economy of poverty, equity and growth: Sri Lanka and Malaysia, Table 28. For Lorenz curves: Calculated by the author from data in Bruton, op. cit. For poverty: For 1970, 1976, and 1984 Bruton, op. cit., Table 30, takcn from data in Fifth Malaysian Plan, 1986-1990, p. 86; for 1979 calculated by the author from unpublished tabulations from the 1980 Household Income Survey.

Source: Fields $(1989,23-24)$. 


\section{References}

Adelman, Irma and Cynthia Taft Morris, 1973, Economic growth and social equity in developing countries (Stanford University Press, Palo Alto, CA).

Ahluwalia, Montek, Nicholas Carter and Hollis Chenery, 1979, Growth and poverty in developing countries, in: Hollis Chenery, ed., Structural change and development policy (Oxford University Press, New York).

Altimir, Oscar, 1993, Income distribution and poverty through crisis and adjustment, in: G. Bird and A. Helwege, eds., Latin American economic recovery, forthcoming.

Atkinson, A.B. and F. Bourguignon, 1987, Income distribution and differences in needs, in: G.R. Feiwel, ed., Arrow and the foundations of the theory of economic policy (MacMillan, New York).

Bardhan, Pranab K., 1974, The pattern of income distribution in India: A review, in: T.N. Srinivasan and P.K. Bardhan, eds., Poverty and income distribution in India (Statistical Publishing Society, Calcutta).

CEPAL, 1990, Magnitüd de la pobreza en America Latina en los anos ochenta, Mayo.

Chen, Shaohua, Gaurav Datt and Martin Ravallion, 1993, Is poverty increasing in the developing world? (World Bank, Washington, DC) April.

Fields, Gary S., 1980, Poverty, inequality, and development (Cambridge University Press, New York).

Fields, Gary S., 1989, A compendium of data on inequality and poverty for the developing world (Cornell University, Ithaca, NY) March.

Fields, Gary S., 1991, Growth and income distribution, in: George Psachaopoulos, ed., Essays on poverty, equity and growth (Pergamon Press, Oxford).

Fields, Gary S., 1992, Changing poverty and inequality in Latin America, Public Finance.

Foster, James, Joel Greer and Erik Thorbecke, 1984, A class of decomposable poverty measures, Econometrica.

Haddad, Lawrence and Ravi Kanbur, 1990, How serious is the neglect of intra-household inequality?, The Economic Journal, Sep.

International Labour Office (ILO), 1984, Generating internationally comparable income distribution estimates (ILO, Geneva).

Jain, Shail, 1975, Size distribution of income: A compilation of data (World Bank, Washington, DC).

Londono, Juan Luis, 1989, Income distribution in Colombia: 1971-88, Basic estimations, Dec.

Morley, Samuel A., 1992, Macroconditions and poverty in Latin America, Inter-American Development Bank, Feb.

Paukert, Felix, 1973, Income distribution at different levels of development: A survey of evidence, International Labour Review, Aug.-Sep.

Ravallion, Martin, 1993, Growth, inequality and poverty: New evidence on old questions (World Bank, Washinton, DC) March.

Sen, Amartya K., 1976, Poverty: An ordinal approach to measurement, Econometrica, March.

Sen, Amartya K., 1984, Family and food: Sex bias in poverty, in: A.K. Sen, ed., Resources, values and development (Harvard University Press, Cambridge, MA).

Tabatabai, Hamid, 1993, The incidence of poverty in developing countries: An ILO compendium of data (ILO, Geneva).

United Nations, 1981, A survey of national sources of income distribution statistics (United Nations, New York).

United Nations, 1985, National accounts statistics: Compendium of income distribution statistics (United Nations, New York).

United Nations, 1990, Human development report (United Nations, New York).

Urrutia, Miguel, 1985, Winners and losers in Colombia's economic growth of the 1970s (Oxford University Press, New York). 
Webb, Richard, 1988, The political economy of poverty, equity and growth: Peru, 1948-85 (World Bank, Washington, DC) July.

World Bank, World Development Report, various issues 